\title{
Symposium: Systematic Reviews and the Dental Research Agenda
}

\author{
Derek Richards \\ Centre for Evidence-based Dentistry, Institute of Health Sciences, Oxford, UK
}

\author{
The Systematic Reviews and the Dental Research Agenda symposium was held in \\ Cardiff, Wales during the First Pan-European Federation of the International \\ Association of Dental Research (IADR). The symposium was organised by Dr I \\ Chestnutt from the Cardiff Dental School and chaired by Professor SA Williams of \\ Leeds Dental School. The meeting examined the strengths and weaknesses and \\ advantages and disadvantages of systematic reviews, addressing the questions: \\ What are systematic reviews? \\ How topics are chosen for systematic reviews? \\ The potential of systematic reviews to direct future dental research, and \\ How systematic reviews can alter clinical practice? \\ Evidence-Based Dentistry (2003) 4, 19-20. doi:10.1038/sj.ebd.6400166
}

\section{Systematic reviews in dentistry}

The excellent symposium contained four high-quality presentations from wellknown leaders in the field of systematic reviewing. The meeting was opened by Professor Kleijnen, the Director of the UK National Health Service (NHS) Centre for Reviews and Dissemination (CRD) at the University of York, UK, who expertly guided the audience through the general process of conducting a systematic review. He explored positive and negative aspects of such reviews, using examples from the extensive range of studies conducted by the CRD in York, including the recent fluoridation review. He also gave some examples of how systematic reviews had changed practice; for example, the use of human albumin for resuscitation and volume expansion in critically injured patients. ${ }^{1}$

Professor Asbjorn Jokstad from Department of Dental Prosthetics and Oral Function University of Oslo, Norway began his presentation with a historical overview, highlighting the rise in the number of review articles in the field over the past 30 years. This has risen to around 9000 per annum at present. Professor Jokstad also noted that this increase has been mirrored by a dramatic rise in the numbers of dental journals available! He noted a similar increase in the number of systematic reviews, so that
Table 1. Systematic reviews in dental and related topics.

\begin{tabular}{lc}
\hline Topics & Systematic reviews $(n)$ \\
\hline Pain/pharmacotherapy & 51 \\
Periodontology & 31 \\
Restorative dentistry & 28 \\
Caries & 23 \\
Fluoride issues & 17 \\
Orthodontics & 16 \\
Implant-related & 11 \\
\hline
\end{tabular}

dentistry-related reviews are now available on a wide range of topics (see Table 1 ). Not all these reviews are of equal quality, however. Using as examples recent dental systematic reviews of guided tissue regeneration, ${ }^{2-4}$ dental implants, ${ }^{5}$ temporomandibular disorders ${ }^{6,7}$ and dental caries, ${ }^{8}$ he drew the audience's attention to their differing conclusions and emphasis, highlighting the impact of review methodology and study-selection procedures on the conclusions. Professor Jokstad also noted the need for better methodological design of primary studies, and the necessity to define valid diagnostic criteria and treatment-outcome criteria. A further question from Professor Jokstad asked who is responsible for the dissemination and implementation of the results of highquality reviews, as the majority of the profession were unaware of them, a point raised again by later speakers.

\section{Systematic reviews and the dental research agenda}

Professor Elizabeth Treasure from the Dental Public Health Unit, University of Wales College of Medicine, Cardiff, Wales, used her experience of being involved in a number of dental systematic reviews to identify a number of common themes that arise in them:

- Limited number of studies

- Some reviews found no studies that might be included

- Poor-quality evidence

- Poor reporting of data

- Frequently unable to combine studies.

These pitfalls have resulted in dental systematic reviews that produce a number of common recommendations. There is clearly a need for more well-designed randomised controlled trials and observational studies. The current poor quality of trial reporting should be addressed by the adoption of internationally recognised standards of reporting such as CONSORT (Consolidated Standards of Reporting of Trials; www.consort-statement.org), she said. Professor Treasure described how evaluating the dental evidence-base can reveal fantastic detail on dental procedures within study designs that range from very good to very poor, but overall the quality of reporting and data analysis is poor. She then issued a challenge to the dental research community to raise the quality of their research to the highest current standards.

She concluded that systematic reviews are important because they provide a wide review of the available evidence. They can clarify what is known about a subject in a critique of what has been done and what should be done. She noted that there is now an appreciation of the need to train researchers in the methodology of systematic reviewing and also a wider need for everyone to understand the process. The overall aim should be to emphasise the importance of systematic reviews in evidence-based 
healthcare and they should be key to new research applications.

\section{Systematic reviews and changing clinical practice}

In the final presentation, Professor Nigel Pitts, Director of the Dental Health Services Research Unit at the University of Dundee, Scotland, addressed the relationship between systematic reviews and clinical guidelines and whether systematic reviews can alter clinical practice.

Professor Pitts initially discussed the view that evidence-based practice was not just one activity but a whole matrix of related activities. Systematic reviews therefore impact upon a range of areas, from health policy, research, undergraduate and postgraduate education, and dental practice, to the funding and organisation of care.

He then looked at the impact of two systematic reviews in dentistry, one describing the longevity of dental restorations, ${ }^{9}$ and the other the use of pit and fissure sealants, ${ }^{10}$ concluding that there had been some impact but that overall they had had little effect. Discussing the possible impact of the use of evidencebased guidelines in changing practice, Professor Pitts then described the work done by the Scottish Intercollegiate Guidelines Network (SIGN; www.sign. ac.uk) in developing two dental guidelines ${ }^{11,12}$ and their mixed experiences with implementation. He also touched on the development of two new SIGN guidelines (on caries prevention for the preschool child and on orofacial cancer), and the work of the dental faculties of the Royal Colleges and others in guide- line development. The work of the AGREE (Appraisal of Guidelines Research and Evaluation; www.agreecollaboration.org/) in the development of a tool for assessing the quality of guidelines was also brought to the audience's attention.

Professor Pitts closed his presentation by touching on the development of 'clinical-effectiveness' protocols in Scotland and evidence-based clinical pathways for NHS primary dental care in England and Wales, which he regards as having the potential to improve the movement of evidence into practice. He also noted the increasing need to coordinate evidence-based dental activity both nationally and internationally to reduce unnecessary duplication of effort, touching on the efforts to improve this.

The presentations finished with a lively discussion, with an audience possessing not a little collective experience in the field itself. The consensus of the symposium was that systematic reviews are important if not vital to the furthering of dental research in that they can both provide systematic summaries of current knowledge and identify areas for future research. There does need to be greater awareness of the methods and of what reviews are being conducted to avoid duplication. We also need to learn lessons from the mistakes made by medicine in relation to implementing and disseminating the findings of systematic reviews and not repeat them.

1. Alderson $P$, Bunn $F$, Lefebvre $C$, et al. Human albumin solution for resuscitation and volume expansion in critically ill patients (Cochrane Review). In The Cochrane Library. Oxford: Update Software; 2003: issue 1.
2. Laurell L, Gottlow I, Zybutz M, Persson R. Treatment of intrabony defects by different surgical procedures. A literature review. J Periodontol 1998; 69:303-133.

3. Cortellini P, Tonetti MS. Focus on intrabony defects: guided tissue regeneration. Periodontology 2000; 22:104-132.

4. Needleman IG, Giedrys-Leeper E, Tucker RJ, Worthington HV. Guided tissue regeneration for periodontal infra-bony defects (Cochrane Review). In The Cochrane Library. Oxford: Update Software; 2003: issue 1.

5. Esposito M, Coulthard P, Worthington HV, Jokstad A. Quality assessment of randomised controlled trials of oral implants. Int I Oral Maxillofacial Implants 2001; 16:783-792.

6. Forssell H, Kalso E, Koskela P, Vehmanen R, Puukka P, Alanen P. Occlusal treatments in temporomandibular disorders: a qualitative systematic review of randomised controlled trials. Pain 1999; 83:549-560.

7. Dao TT, Lavigne GJ. Oral splints: the crutches for temporomandibular disorders and bruxism. Crit Rev Oral Biol Med 1998; 9:345-361.

8. US National Institutes for Health, Diagnosis and Management of Dental Caries Throughout Life. NIH Consensus Statement. Bethesda: National Institutes for Health 2001; 18:1-24.

9. UK National Health Service Centre for Reviews and Dissemination, The longevity of dental restorations: a systematic review. York: National Health Service Centre for Reviews and Dissemination 2001; 337.

10. Llodra JC, Bravo M, Delgado-Rodriguez M, Baca $P$, Galvez R. Factors influencing the effectiveness of sealants - a meta-analysis. Community Dent Oral Epidemiol 1993; 21:261-268.

11. Scottish Intercollegiate Guidelines Network. Preventing Dental Caries in Children at High Caries Risk. Targeted Prevention of Dental Caries in the Permanent Teeth of 6-16 Year-olds. Presenting For Dental Care. SIGN Executive, Royal College of Physicians Edinburgh Scottish Intercollegiate Guidelines Network, 2000.

12. Scottish Intercollegiate Guidelines Network. Management of Unerupted and Impacted Third Molar Teeth. SIGN Executive, Royal College of Physicians Edinburgh Scottish Intercollegiate Guidelines Network, 2000, 1999.

Evidence Based Dentistry (2003) 4, 19-20. doi:10.1038/sj.ebd.6400166 